\title{
Baja prevalencia y complicaciones del prolapso de válvula mitral en pacientes ambulatorios
}

\author{
Prevalence and clinical outcome of mitral-valve prolapse. Freed LA, Levy D, Levine RA, et al. N Engl J Med 1999; $341,1-7$.
}

\author{
Objetivo \\ Determinar la prevalencia de prolapso de válvula mitral (PVM) y sus \\ asociaciones clínicas en una población de pacientes ambulatorios.

\section{Diseño} \\ Estudio de corte transversal. \\ Lugar \\ Cohorte de descendientes de pacientes del Estudio Framingham.
}

\section{Pacientes}

Un total de 3491 sujetos de la población general fueron incluidos en el estudio. Se examinaron los ecocardiogramas transtoráxicos de 1845 hombres y 1646 mujeres. La edad promedio fue de 54,7 \pm 10 años. Se excluyeron aquellos con ecocardiogramas técnicamente inadecuados.

\section{Métodos \\ El PVM se dividió en clásico (desplazamiento superior de las valvas de más de $2 \mathrm{~mm}$ durante la sístole y engrosamiento mayor o igual a $5 \mathrm{~mm}$ en diástole y no clásico (desplazamiento de más de $2 \mathrm{~mm}$ du- rante la sístole con engrosamiento menor a $5 \mathrm{~mm}$ en la diástole).}

\section{Resultados principales}

De los 3491 sujetos, 84 (el 2,4\%) presentaron PVM. De estos, en 47 pacientes $(1,3 \%)$ el prolapso fue clásico, mientras que en 37 $(1,1 \%)$ fue no clásico. La distribución de sexo y edad fue similar en ambos grupos.

La prevalencia de distintas patologías fue similar en pacientes con y sin prolapso: historia de insuficiencia cardíaca $(1,2 \%$ vs. $0,7 \%)$; fibrilación auricular (1,2\% vs. 1,7\%); enfermedad cerebrovascular $(1,2 \%$ vs. $1,5 \%)$ y síncope $(3,6 \%$ vs. $3 \%)$ respectivamente. Los sujetos con prolapso fueron más delgados $(p<0,001)$ y presentaron mayor grado de reflujo mitral que aquellos sin prolapso. El reflujo, en promedio, fue clasificado como mínimo o leve.

Se evidenció reflujo mitral severo en $7 \%$ de los pacientes con prolapso clásico, en $0,5 \%$ en pacientes sin prolapso y en ningún paciente con prolapso no clásico.

Las frecuencias de dolor precordial, disnea y alteraciones electrocardiográficas fue también similar en los pacientes con o sin prolapso (ajustado por edad, sexo e índice de masa corporal).

\section{Conclusión}

En una muestra no seleccionada de pacientes ambulatorios la prevalencia del prolàpso de válvula mitral fue más baja que la reportada previamente. A su vez, la prevalencia de consecuencias clínicas adversas asociadas al prolapso de válvula mitral fue baja.

\section{COMENTARIO}

En las dos décadas pasadas han emergido algunos conceptos que clarificaron el diagnóstico y el pronóstico del prolapso de la válvula mitral 1: a) la aplicación del ecocardiograma modo M en el diagnóstico de esta patología generó una prevalencia mayor de 30\% en jóvenes sanos; b) posteriormente se reconoció la morfología en " silla de montar" de las valvas que simulaban la apariencia de prolapso en ciertas vistas ecocardiográficas 2; c) al prolapso mitral se lo asoció con un espectro de anormalidades clínicas, ecocardiográficas y patológicas; y d) es aún más importante reconocer que dentro del espectro de la patología (con la definición genérica de prolapso) hay un subgrupo de pacientes que presentan la forma primaria de PVM 3 consistente en valvas redundantes con marcada proliferación mixomatosa y elongación del aparato cordal (que presentan riesgo de complicaciones) y otro subgrupo con una variante normal de PVM referida al abombamiento durante la sístole hacia la aurícula izquierda de valvas con apariencia normal, que no presentan riesgo de complicaciones.

El trabajo de Freed y col. tiene las ventajas de utilizar el criterio actual de PVM por ecocardiografía y de estar realizado en la población general. El mismo demuestra que la prevalencia de esta patología es baja $(2,4 \%)$ en la comunidad. Estos datos, que contrastan con otros de la literatura, nos lleva a considerar de utilidad las siguientes conductas: a) que todos los laboratorios de ecocardiografía tengan el mismo criterio de prolapso y b) que los ecocardiografistas informen a los clínicos los hallazgos morfológicos de sus pacientes más allá del diagnóstico. Esto se fundamenta en que los pacientes con valvas redundantes y engrosadas presentan un riesgo mayor de complicaciones que aquellos que no presentan esta morfología (valvas que sólo abomban hacia la aurícula izquierda en sístole), cuyo riesgo de eventos adversos es similar a la población general. En pacientes con forma primaria de PVM se aconseja un seguimiento meticuloso y profilaxis contra endocarditis infecciosa, no así en la variante normal de PVM, donde la profilaxis es opcional 4. Aquellos pacientes con soplo ó click característico deben realizarse un examen ecocardiográfico para descartar PVM. En cambio, el ecocrdiograma no debe ser parte del estudio rutinario de los pacientes con dolor precordial atípico, palpitaciones, ansiedad y otros síntomas no cardíacos.

La información que nos aporta el trabajo de Freed y col. nos ayuda a una mejor comprensión y una aproximación más racional de esta patología.

\section{Dr. Rodolfo Pizarro}

Servicio de Cardiología. Hospital Italiano de Buenos Aires.

\section{Referencias}

1-Levy D, Savage D. Prevalence and clinical features of mitral valve prolapse. Am Heart J 1987;113;1281-1290.

2-Levine RA, Triulzi MO, Harrigan P, y col. The relationship of mitral annular shape to the diagnosis of mitral valve prolapse.Circulation 1987; $75 ; 756-767$.

3-Nidorf SM, Weyman AE, Hennessey $R$, y col. The relationship between mitral valve morphology and prognosis in patients with mitral valve prolapse: a prospective echocardiographic study of 568 patients. J Am Soc Echocardiogr 1993; $6 ; 58$.

4-Deveraux RB, Kramer - Fox R, Kligfield P, y col. Mitral valve prolapse: causes, clinical manifestations, and management. Ann Int Med 1989; 11;305-317. 